\title{
Mourning Geckos (Lepidodactylus lugubris) Established on Abaco Island, The Bahamas
}

\author{
Sean T. Giery ${ }^{1}$, Jessica N. Pita-Aquino ${ }^{2}$, Jason Kolbe ${ }^{2}$, and Jonah Piovia-Scott ${ }^{3}$ \\ ${ }^{1}$ Department of Biology, The Pennsylvania State University, University Park, Pennsylvania 16802 (stgiery@gmail.com) \\ ${ }^{2}$ Department of Biological Sciences, University of Rhode Island, Kingston, Rhode Island 02881 \\ ${ }^{3}$ School of Biological Sciences, Washington State University Vancouver, Vancouver, Washington 98686
}

\begin{abstract}
A 2030-2300 h on 15-21 September 2018, we encountered Mourning Geckos (Lepidodactylus lugubris) while searching 3.4 ha of bushes, trees, and buildings in a residential complex located at the eastern end of Marsh Harbour, Abaco Island, The Bahamas $\left(26.544274^{\circ} \mathrm{N},-77.049793^{\circ} \mathrm{W}\right.$; WGS 84). The habitat consisted of landscaped vegetation and bordering coppice surrounding this seaside complex. We observed no juveniles or hatchlings but did see as many as five individuals on a given night. During a subsequent visit on 15-22 May 2019, we did see two juveniles and at least one gravid female, providing direct evidence of reproduction. Most Mourning Geckos were observed using distal branches of ornamental shrubs (e.g., Nerium oleander, Ixora sp.), small trees (e.g., Conocarpus erectus), Coconut Palm fronds (Cocos nucifera), and Screw Pine (Pandanus utilis) thickets. During the second visit, they also were observed using artificial structures (e.g., buildings and painted concrete walls), and several appeared to be consuming insects attracted to artificial lights. Coleman Sheehy III at the Florida Museum of Natural History verified the identity of the geckos from a photographic voucher (FMNH 188143).
\end{abstract}

The establishment of L. lugubris on Abaco marks the seventh species of nonnative reptile and amphibian established on Abaco, four of which have become established within the last decade (Knapp et al. 2011; Powell et al. 2012; Giery 2013; Giery et al. 2017; Reynolds and Giery in press). Notably, invasion occurred despite a relatively diverse vertebrate community. At this site in Marsh Harbour, six additional species of lizards are abundant: Brown Anole (Anolis sagrei), Bark Anole (A. distichus), Bahamian Green Anole (A. smaragdinus), Tropical House Gecko (Hemidactylus mabouia), Ocellated Gecko (Sphaerodactylus notatus), and Northern Curlytail (Leiocephalus cairnatus). Predators such as the Northern Bahamas Boa (Chilabothrus exsul), Cuban Treefrogs (Osteopilus septentrionalis), domestic cats (Felis silvestris catus), and Black Rats (Rattus rattus) are commonly seen as well (Reynolds et al. 2016). No additional areas were surveyed for these lizards and their distribution in the wider Marsh Harbour area and on Abaco Island is unknown. However, given an ability to invade diverse communities and use a variety of habitats, expansion on Abaco Island is likely.
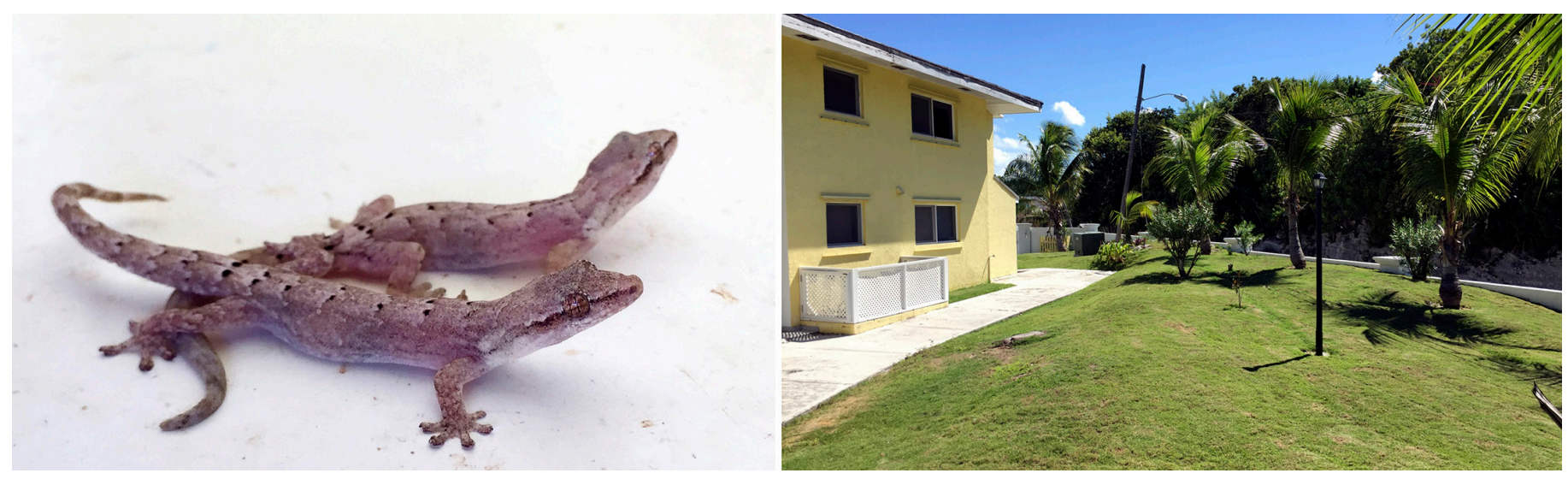

Fig. 1. Two adult Mourning Geckos (Lepidodactylus lugubris) found in Marsh Harbour, Abaco Island, The Bahamas in September 2018 (left) and the habitat in which they were found (a multi-unit residential complex composed of landscaped vegetation and abundant artificial surfaces; right). Photographs by S. Giery. 
Mourning Geckos have been well-established human commensals along the Pacific Coast of Central and South America (Panama, Costa Rica, Colombia, and Ecuador) since before the start of the 20th century (Smith and Grant 1961; Myers and Rand 1969; Hoogmoed and Avila-Pires 2015). However, their dispersal along the Atlantic Coast has been much slower. Although established in the Panama Canal Zone since 1919 and the Nicaraguan coast since -1976 (Hoogmoed and Avila-Pires 2015), only recently has the species become established in the Greater Caribbean: Curacao, Guadeloupe, Grand Cayman, Cuba, The Bahamas, Utila (Honduras), Costa Rica, Venezuela, Colombia, Suriname, and Florida (Bauer et al. 2007; Knapp et al. 2011; Krysko et al. 2011; Lorvelec et al. 2011, 2017; Daza et al. 2012; Hoogmoed and Avila-Pires 2015; Jimenez and Abarca 2015; Krysko and Mackenzie-Krysko 2016; Senaris et al. 2017; Bosch and Páez 2017; Borroto-Páez 2018; Goetz and Burton 2018; Johnson et al. 2018; Behm et al. 2019; Brown and Diotallevi 2019; Liebgold et al. 2019).

The range expansion of Mourning Geckos in the Greater Caribbean Region is ongoing and proceeding rapidly. Indeed, many of these invasions have being reported since 2009. We attribute this invasive potential to broad habitat tolerance, ability to invade diverse communities, and parthenogenic reproduction. We expect that this rapid expansion among and within islands of the Greater Caribbean region is likely to continue.

\section{Literature Cited}

Bauer, A.M., T.R. Jackman, E. Greenbaum, and T.J. Papenfuss. 2007. First record of Lepidodactylus lugubris in Suriname. Applied Herpetology 4: 84-85.

Behm, J., G. Van Buurt, B.M. DiMarco, J. Ellers, C.G. Irian, K.E. Langhans, K. McGrath, T.J. Tran, and M.R. Helmus. 2019. First records of the Mourning Gecko (Lepidodactylus lugubris Duméril and Bibron, 1836), Common House Gecko (Hemidactylus frenatus in Duméril, 1836), and Tokay Gecko (Gekko gecko Linnaeus, 1758) on Curaçao, Dutch Antilles, and remarks on their Caribbean distributions. BioInvasions Records 8: 34-44.

Borroto-Páez, R. 2018. High abundance of the introduced Mourning Gecko (Lepidodactylus lugubris) in southwestern Grande Terre, Guadeloupe, French West Indies. Reptiles \& Amphibians 25: 184-187.

Bosch, R.A. and R.B. Páez. 2017. First record from Cuba of the introduced Mourning Gecko, Lepidodactylus lugubris (Duméril and Bibron, 1836). BioInvasions Records 6: 297-300.

Brown, T.W. and F. Diotallevi. 2019. Confirmation of the Mourning Gecko, Lepidodactylus lugubris (Duméril and Bibron 1836), on Isla de Utila, with remarks on the island's invasive reptiles. Reptiles \& Amphibians 26: 151-154.

Daza, J.D., S.L. Travers, and A.M. Bauer. 2012. New records of the Mourning Gecko Lepidodactylus lugubris (Duméril and Bibron, 1836) (Squamata: Gekkonidae) from Colombia. Check List 8: 164-167.

Giery, S.T. 2013. First records of Red Cornsnakes (Pantherophis guttatus) from
Abaco Island, The Bahamas, and notes of their current distribution in the Greater Caribbean region. Reptiles \& Amphibians 20: 36-39.

Giery, S.T., D. Richard, and J.T. Stroud. 2017. Establishment of the Eastern Narrowmouthed Frog (Gastrophryne carolinensis) on Abaco Island in The Bahamas, with notes on the species' current distribution in the West Indies. Reptiles \& Amphibians 24: 139-141.

Goetz, M. and F.J. Burton. 2018. First record of the Mourning Gecko, Lepidodactylus lugubris (Duméril \& Bibron 1836), on Grand Cayman, Cayman Islands. Reptiles \& Amphibians 25: 158-159.

Hoogmoed, M.S. and T.C.S. Avila-Pires. 2015. Lepidodactylus lugubris (Duméril \& Bibron 1836) (Reptilia: Gekkonidae), an introduced lizard new for Brazil, with remarks on and correction of its distribution in the New World. Zootaxa 4000: 90-110.

Jimenez, R.R. and J.G. Abarca. 2015. Records for the Mourning Gecko (Lepidodactylus lugubris) and its expansion in Costa Rica. Mesoamerican Herpetology 2: 214-217.

Johnson, S., S.D. Buckner, and D. Knowles. 2018. Another parthenogenetic species of gecko on New Providence Island, The Bahamas. Reptiles \& Amphibians 25: $215-216$.

Knapp, C.R., J.B. Iverson, S.D. Buckner, and S.V Cant. 2011. Conservation of amphibians and reptiles in The Bahamas, pp. 53-87. Conservation of Caribbean Island Herpetofaunas, Volume 2: Regional Accounts of the West Indies. Brill, Leiden, The Netherlands.

Krysko, K.L. and C. Mackenzie-Krysko. 2016. First report of the Mourning Gecko, Lepidodactylus lugubris (Duméril \& Bibron 1836), from The Bahamas. Caribbean Herpetology 45: 1-2.

Krysko, K.L., K.M. Enge, and P.E. Moler. 2011. Atlas of Amphibians and Reptiles in Florida. Final Report, Project Agreement 08013, Florida Fish and Wildlife Conservation Commission, Tallahassee, Florida.

Liebgold, E.B., H.L. Liebgold, M.J. Ransom, and T.S. Ransom. 2019. The spread of the parthenogenetic Mourning Gecko, Lepidodactylus lugubris (Duméril and Bibron, 1836) to Paradise Island, The Bahamas, with comments on citizen science observations of non-native herpetofauna. BioInvasions Records 8: 45-49.

Lorvelec, O., A. Levesque, and A.M. Bauer. 2011. First record of the Mourning Gecko (Lepidodactylus lugubris) on Guadeloupe, French West Indies. Herpetology Notes 4: 291-294.

Lorvelec, O., N. Barré, and A.M. Bauer. 2017. The status of the introduced Mourning Gecko (Lepidodactylus lugubris) in Guadeloupe (French Antilles) and the high probability of introduction of other species with the same pattern of distribution. Caribbean Herpetology 57: 1-6.

Myers, C.W. and A.S. Rand. 1969. Checklist of amphibians and reptiles of Barro Colorado Island, Panama, with comments on faunal change and sampling. Smithsonian Contributions to Zoology 10: 1-11.

Powell, R. and R.W. Henderson (eds.). 2012. Island lists of West Indian amphibians and reptiles. Bulletin of the Florida Museum of Natural History 51: 85-166.

Reynolds, R.G. and S.T. Giery. In press. Amphibians of the Bahamas and Turks \& Caicos Islands. In: H. Heatwole and N. Rios-Lopez (eds.), Amphibian Biology, Volume 9, Part 5: Status of Decline of Amphibians: Western Hemisphere: The Caribbean. Pelagic Press, Exeter, United Kingdom.

Reynolds, R.G., S.T. Giery, W.A.M. Jesse, and Q.N. Quach. 2016. Preliminary assessment of road mortality in Chilabothrus exsul, the Northern Bahamas Boa. Caribbean Naturalist 34: 1-10.

Senaris, C., F.J.M. Rojas-Runjaic, M.M. Aristeguieta, and G. Garcia-Senaris. 2017. Second record of the invasive gecko Lepidodactylus lugubris (Duméril \& Bibron, 1836) (Squamata: Gekkonidae) from Venezuela. Check List 13: 1-4.

Smith, H.M. and C. Grant. 1961. The Mourning Gecko in the Americas. Herpetologica 17: 68. 